\title{
Thermodynamic analysis and potential efficiency improvements of a biochemical process for lignocellulosic biofuel production
}

\author{
M. Imroz Sohel ${ }^{*}$ and Michael W. Jack \\ Scion, Te Papa Tipu Innovation Park, 49 Sala Street, Rotorua, New Zealand \\ * Corresponding author. Tel: +64 7 3435730; fax: +64 7 3435375; E-mail address: \\ mohammed.sohel@scionresearch.com
}

\begin{abstract}
This paper presents a thermodynamic analysis of a biochemical process for the production of bioethanol from a lignocellulosic feedstock. The major inefficiencies in the process are identified as: i) the combustion of lignin for process heat and power production and ii) the simultaneous saccharification and fermentation process. As lignin is not converted to ethanol and lignin has a high value of chemical exergy, the overall efficiency of the biochemical process largely depends on how the lignin is utilized. We therefore consider integrating a source of low temperature heat, such as waste heat or low-enthalpy geothermal heat, into a biochemical lignocellulosic biorefinery to provide process heat. This enables the lignin-enriched residue to be used either as a feedstock for chemicals and materials or for on-site electricity generation. Our analysis shows that integrating low temperature heat source into a biorefinery in this way represents an improvement in overall resource utilization efficiency.
\end{abstract}

Keywords: Bioenergy; biorefinery; geothermal energy; process heat; integrated approach.

\section{Nomenclature}

\begin{tabular}{|c|c|c|}
\hline Ex &.$M J \cdot s^{-1}$ & heat transfer \\
\hline$P$ & electric power. & ............physical \\
\hline & efficiency........ & proc ….................................... process \\
\hline & exergy loss for heat transfer....... & ......................... product \\
\hline$u b$ & cript & wstprd .......................................... product \\
\hline io & & 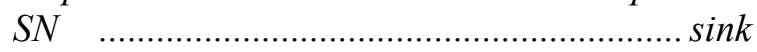 \\
\hline$c h$ & ..cher & ...... source \\
\hline Tro & 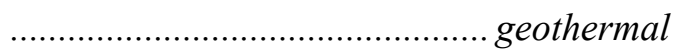 & dead state \\
\hline
\end{tabular}

\section{Introduction}

Increasing the percentage of liquid transport fuel from renewable biomass sources is an important opportunity in the move towards a more sustainable energy system. Recent political and research and development trends show a clear move towards lignocellulosic feedstocks for these biofuels [1]. Lignocellulosic feedstocks mitigate competition for land and water used for food production, increase biomass production per unit of land and reduce the inputs needed to grow the biomass [2-4].

A key challenge for biofuel production systems is to develop efficient conversion technologies which are able to compete economically with fossil fuels. The biorefinery concept [5, 6], where a range of high-value co-products are produced in addition to commodity fuel products, attempts to achieve increased efficiency by making full use of biomass feedstocks [5, 7-9]. Due to the potential cost reductions from this strategy, biorefineries are seen as a key step towards the commercial implementation of biofuels [5].

A large percentage of the lignocellulosic biorefinery concepts that have so far been proposed are based on a biochemical conversion platform where the polysaccharides in lignocellulosic material are converted to liquid fuel using enzymes [10,11]. In these systems it has been proposed that the lignin by-product and other extractives can be used for higher value uses 
such as the production of high-value chemicals and materials [5, 7] or on-site electricity production [12].

One of the major impediments to the lignocellulosic biorefinery concept is that the liquid fuel production from lignocellulosic biomass is a very energy intensive process [5, 11, 13, 14]. Current integrated biorefinery concepts use the lignin-enriched residue as a fuel to meet process energy demands, reducing the possibility of higher-value uses of lignin. A potential option to overcome this is to introduce an external source of low-enthalpy heat, such as geothermal or waste heat, to meet the process heat demand and thereby leave the ligninenriched residue available for higher-value uses.

As with other energy technologies, thermodynamic analysis provides a powerful tool to guide technology selection and research efforts towards more efficient biofuel production systems. Conventional energy analysis based only on the first-law of thermodynamics cannot be used reliably for these purposes as it does not embody second law constraints on energy conversion and erroneously treats all energy types as equal [15].

Exergy analysis is a convenient method of carrying out thermodynamic analysis of complex systems and has been applied to a wide range of different processes, including; energy technology, chemical engineering, transportation and agriculture [16]. A number of authors have recently applied exergy analysis to biofuel production process [17-26]. While a number of exergy analyses of thermochemical pathways exist [18, 19, 22, 23] applications of exergy analysis to biochemical pathways are limited [20, 24, 25].

In paper we present an updated synthesis of our previous work [25, 26] on applying exergy analysis to identifying the inefficiencies in a biochemical process for producing biofuel and evaluating the potential efficiency gains from integrating low-enthalpy heat into the process. The analysis is based on the National Renewable Energy Laboratory (NREL) process [11] for producing ethanol from a lignocellulosic feedstock.

\section{Methodology}

\subsection{Exergy analysis}

Unlike energy, exergy is exempt from the law of conservation. Every irreversible phenomenon causes exergy losses leading to the reduction of the useful effects of the process or to an increased consumption of the original energy source. The main aim of exergy analysis is to identify and quantify the causes of this thermodynamic imperfection in the process under consideration. The methodology of exergy analysis is presented by Szargut et al. [15] and the general approach to applying exergy analysis to biofuel production processes are given in Lu et al. [19] and Prins et al. [21]. One of the major difficulties in applying exergy analysis to biochemical process for biofuel production is that a number of components are not present in standard exergy tables [15]. In our previous work [25], a table of exergy values for these components and the methods used to calculate them are presented.

\subsection{The biochemical production process}

Several process models for the production of ethanol from biomass have been reported in the literature $[11,13,14]$. In particular, in a NREL publication Wooley et al. [11] have described in detail the overall process for ethanol production from wood chips via a process of simultaneous scarification and co-fermentation (SSCF). They considered a process that on average converts about $44.44 \mathrm{~kg} / \mathrm{s}$ of biomass to $5.52 \mathrm{~kg} / \mathrm{s}$ of ethanol. The process utilizes lignin enriched by-products to meet process heat demand. The model showed that such a plant 
can produce more energy than required for process demands. The model includes an integrated power plant capable of producing $44 \mathrm{MW}$ of electricity (33 MW for internal use and $11 \mathrm{MW}$ for export). Piccalo and Bezzo[14] have developed an optimized system by applying pinch analysis to the original system described by Wooley et al. [11]. The analysis presented here is based on this optimized system. An overview of the process is shown in Fig 1.

Following Piccalo and Bezzo [13], the base case considered here processes 160 metric Ton of wet chip per hour, where the composition of the wood chip is cellulose: $22.2 \%$, xylan: $9.9 \%$, arabinan: $0.4 \%$, mannan: $2 \%$, galactan: $0.1 \%$, acetate: $2.4 \%$, lignin: $14.4 \%$, ash: $0.5 \%$, and moisture: $47.9 \%$.

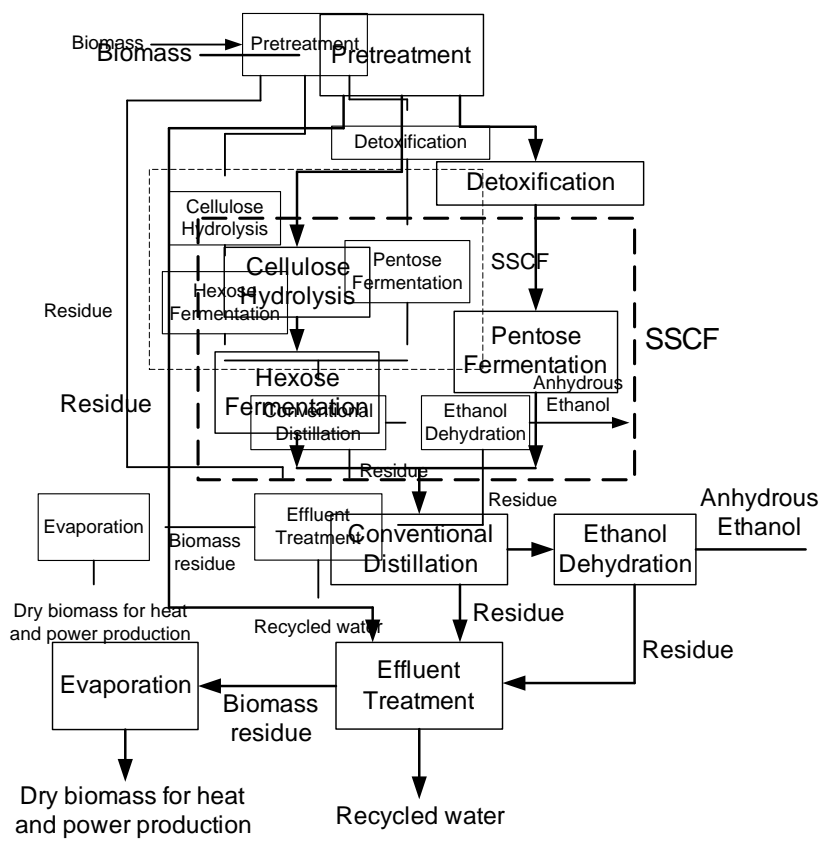

Fig. 1. Process diagram of ethanol production from lignocellulosic biomass

\subsection{The efficiency of biochemical production process}

One of the key parameters that can be evaluated in an exergy analysis is the overall thermodynamic efficiency. The thermodynamic efficiency of a system is defined as [15]:

$\eta=\frac{\text { Exergy of useful products }}{\text { Input Exergy }}$

In the current case, the overall efficiency of ethanol production via the biochemical process described in section 2.2 can be written as

$\eta=\frac{E_{X, \text { Fuel }}+P_{n e t}+E_{X, \text { lignin residue }}}{E_{X, \text { Biomass }}+\sum E_{X, \text { ch }}+E_{X, \text { low temp }}}$

Here, $E_{X, \text { Biomass }}$ is the input chemical exergy of biomass, $\sum E_{X, c h}$ is the sum of the chemical exergies of all input chemicals to the process, $E_{X \text {,low temp }}$ is the exergy of a potential low temperature heat source supplied to the system, $E_{X, F u e l}$ is the chemical exergy of the fuel, 
$E_{X, \text { lignin residue }}$ is the exergy of the lignin-enriched residue and $P_{n e t}$ is the net electricity produced by the system. To evaluate the efficiency of the NREL process described in section 2.2 we put $E_{X, \text { low temp }}=0$ and $E_{X \text {,lignin residue }}=0$.

Exergy analysis can also be used to evaluate thermodynamic losses in each unit process of the system. The exergy balance [27] applied to the system boundary of a unit operation of a process gives

$\sum_{\text {in }} E_{X}=\sum_{\text {out }} E_{X, p r d}+\sum_{\text {out }} E_{X, w s t p r d}+I$

where $\sum_{\text {in }} E_{X}$ is the total input exergy flow, $\sum_{\text {out }} E_{X, p r d}$ is the total output exergy flow in the products, $\sum_{\text {out }} E_{X \text {,wstprd }}$ is the total output exergy flow in the waste products from the unit process and $I$ is the exergy destruction due to internal irreversibility. The last two terms in the exergy balance represent the total exergy loss associated with the unit process. For an irreversible process $I \neq 0$ and Eq. (3) expresses the fundamental property that, unlike energy, exergy is not conserved.

\subsection{Efficiency improvements by integrating a low temperature heat source}

One possibility for improving the efficiency of biofuel production is to integrate a low temperature heat source to meet process heat demands. We consider three discrete cases and calculate the corresponding efficiencies. Here we assume that the internal electricity demand is met from the combustion of lignin-enriched residue. The rejected heat from lignin combustion can also be used to meet all the low temperature heat demand ( $150^{\circ} \mathrm{C}$ or less).

The highest quality steam required for the biorefinery process is $192^{\circ} \mathrm{C}$ (saturated at $13 \mathrm{bar}$ ). This steam demand can be met from any suitable low temperature heat source. The energy required for the highest quality steam is about $46 \mathrm{MW}$ (or 17.6 MW of exergy). We could meet this heat demand by using an external $210^{\circ} \mathrm{C}$ heat source in the biofuel production system, thus integrating heat and biomass resources in a single process. An alternative use for this steam is in an independent power plant. Assuming a typical binary cycle power plant first law efficiency of $15 \%$ [28] we can get about $6.9 \mathrm{MW}$ of electricity from this same heat source. In this work we would like to compare the overall resource efficiency of the integrated vs. independent use of the two resources. We consider 3 cases:

Case 1

This represents the base case, here we operate the biorefinery and the low temperature heat source independently, with the low-temperature heat being used in an independent power plant. The overall efficiency can be calculated from Eq. (2) where, $E_{X, \text { Biomass }}=454.8 \mathrm{MW}$, $\sum E_{X, c h}=12.3 \mathrm{MW}, E_{X, \text { low temp }}=17.6 \mathrm{MW}, E_{X, \text { Fuel }}=147.1 \mathrm{MW}, P_{\text {net }}=17.9 \mathrm{MW}$ and $E_{X, \text { lignin residue }}=0 \mathrm{MW}$. For the biorefinery we use the system described in Section 2.2.

\section{Case 2}

Here we integrate the heat source into the biorefinery to meet the high-temperature heat demands (in the biochemical process) and combust the available lignin-enriched residue to produce additional power. The overall efficiency is calculated from Eq. (2) with $E_{X, \text { Biomass }}=$ 
454.8 MW, $\sum E_{X, c h}=12.3 \mathrm{MW}, E_{X, \text { low temp }}=17.6 \mathrm{MW}, E_{X, F u e l}=147.1 \mathrm{MW}, P_{\text {net }}=22 \mathrm{MW}$ and $E_{X, \text { lignin residue }}=0 \mathrm{MW}$.

Case 3

In this case we meet internal electricity demand from lignin combustion and leave any additional lignin for some higher value use. The overall efficiency is calculated from Eq. (2) with $E_{X, \text { Biomass }}=454.8 \mathrm{MW}, \sum E_{X, c h}=12.3 \mathrm{MW}, E_{X, \text { low temp }}=17.6 \mathrm{MW}, E_{X, \text { Fuel }}=147.1 \mathrm{MW}$, $P_{\text {net }}=0 \mathrm{MW}$ and $E_{X, \text { lignin residue }}=45.8 \mathrm{MW}$.

\section{Results}

\subsection{Exergy analysis of the biofuel production process}

The efficiency of the standard NREL process [11] is calculated to be $34 \%$ using Eq. (2). Fig. 2 (b) provides a breakdown of the exergy losses in various unit operations of the production process. For comparison we have also provided a breakdown of the energy losses in Figure 2 (a). It is clear from the figures that heat and power production is the major contributor to both energy and exergy losses. The second, third and fourth largest contributors to energy loss are evaporation, distillation and dehydration and the pre-treatment \& detox processes, respectively. Unlike the energy losses, the second, third and fourth largest contributors to exergy losses are SSCF, SSCF seed and pre-treatment processes, respectively. Feed handling and lignin separation have similar levels of contribution to energy and exergy losses (less than $1 \%)$.

\subsection{Efficiency improvements by integrating a low temperature heat source}

The calculated overall efficiency for case 1 is $34.0 \%$ which is considered as the base case here. If we integrate the low temperature heat source to the biorefinery (case 2) efficiency becomes $35 \%$. Although, the overall improvement is only $1 \%$, there is a significant improvement in low temperature heat utilization. In particular, an additional 4.1 MW of electricity is generated which represents a $40 \%$ gain in electricity generation from the same low temperature heat source. The overall efficiency for case 3 is $40 \%$. Fig. 3 presents a Grassman diagram of case 3, showing the exergy flow through the various stages of the system.

\section{Discussion and conclusion}

The difference in the breakdown of energy and exergy losses in the system presented in Fig. 2 emphasises the importance of exergy analysis. While both the energy and exergy analysis show that heat and power production is the major loss, there is a significant difference for most of the other unit processes. This difference arises from the fact that first law analysis (energy) treats all forms of energy to be the same, whereas exergy analysis takes into account the available work in different forms of energy. For example, although evaporation, distillation and dehydration are associated with large energy demands, this demand can be met with low temperature heat sources (low exergy sources). In contrast, the SSCF and SSCF seed processes consume very little heat (low exergy) but require a significant amount of electricity (high exergy). A thermochemical process involving gasification and FisherTropsch synthesis was found to have a similar overall efficiency of biochemical process [22]. A more detailed comparison is presented in [25]. 

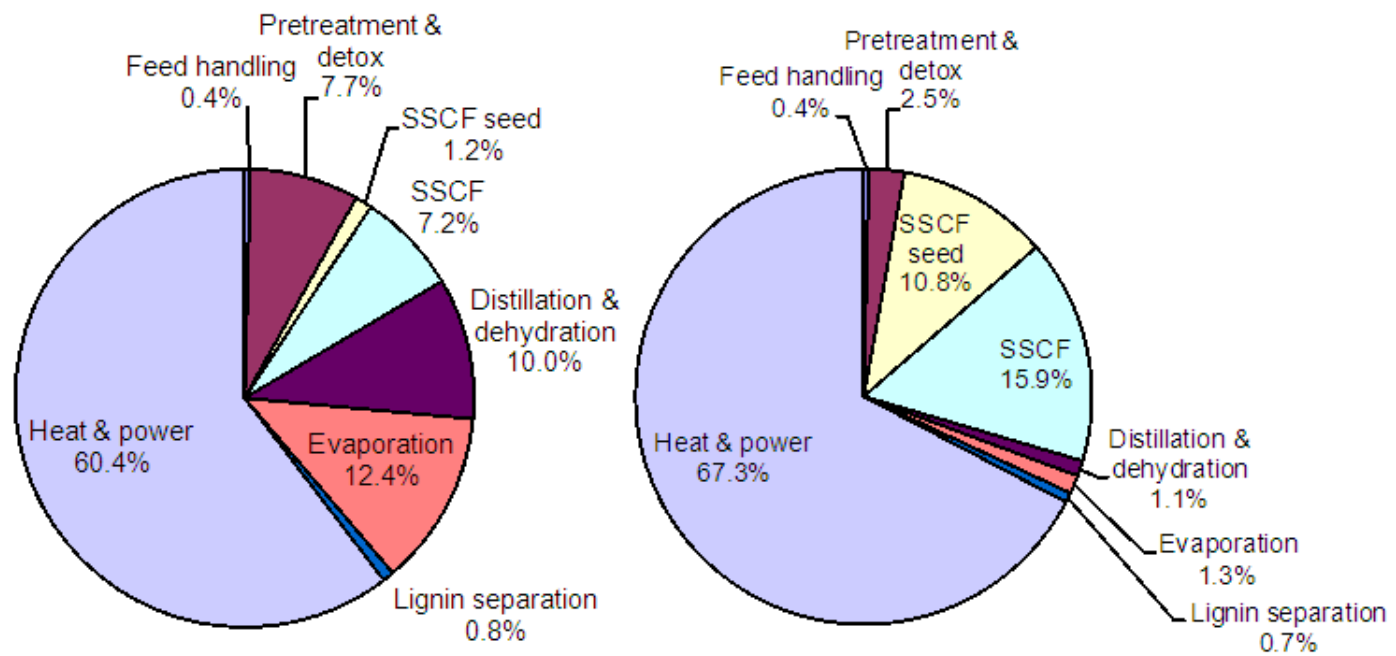

Fig. 2. Breakdown of energy (a) and exergy (b) losses for a biochemical process of biofuel production from lignocellulosic feed stock.

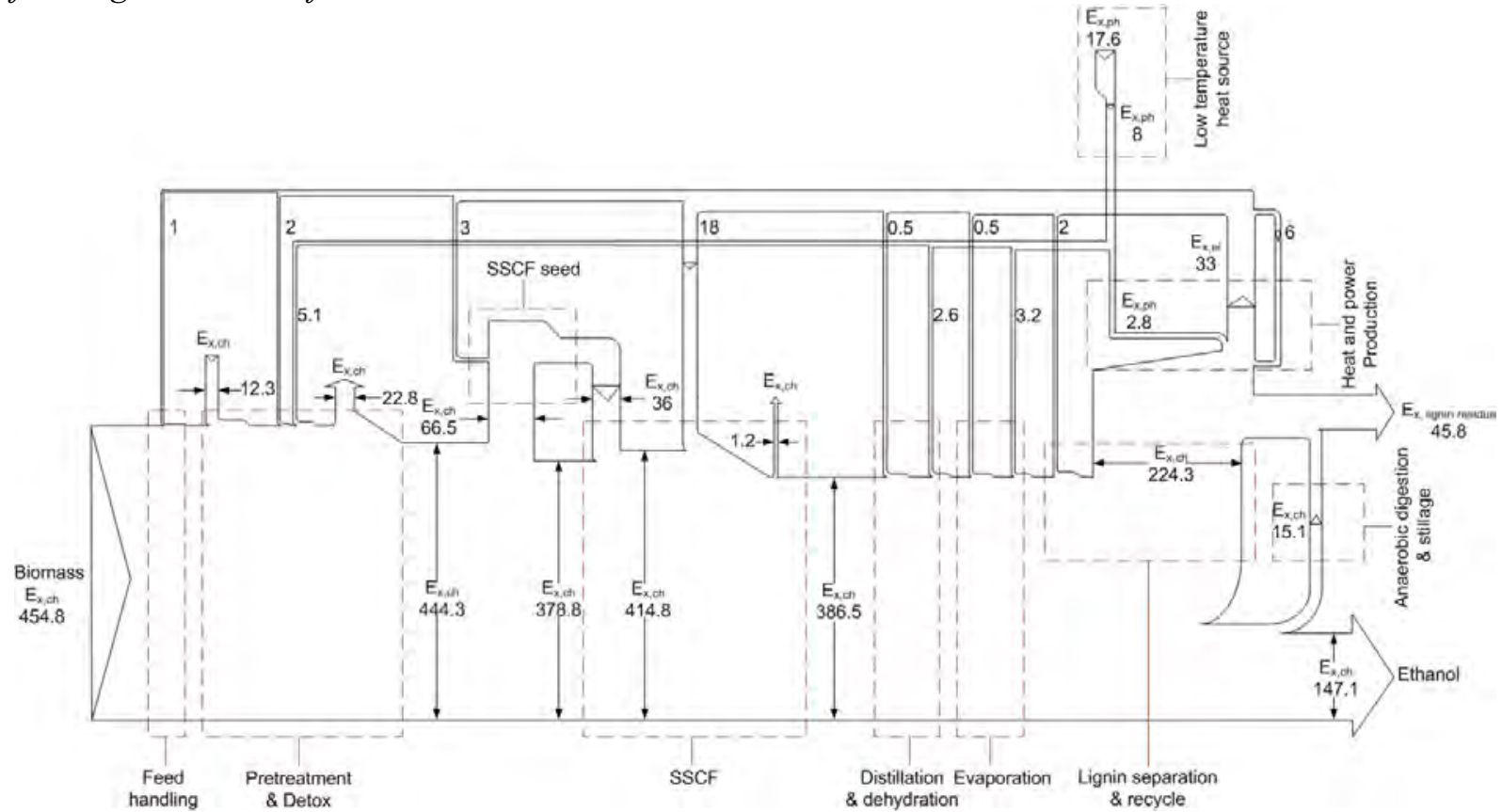

Fig. 3. Grassman diagram for an ethanol and lignin-enriched residue production process where the $192^{\circ} \mathrm{C}$ heat demand is met from low temperature heat source and the remaining internal electricity demand is met from lignin combustion

There are two main reasons that heat and power generation is the largest area of exergy loss in the process. Firstly, due to the inherent inefficiency of combustion, much of the chemical exergy in the lignin is lost. The Carnot efficiency places limits on the ability of future technologies to improve this efficiency. Secondly, the direct reduction in temperature from the combustion temperature $\left(815^{\circ} \mathrm{C}\right.$ for lignin) to that of the process heat $\left(200^{\circ} \mathrm{C}\right)$ leads to a further loss of exergy. The exergy loss due to entropy generation associated with heat transfer to a cooler medium can be easily deduced from the Carnot efficiency [15]

$$
\delta_{H T}=\frac{T_{0}}{T_{S N}}\left(\frac{T_{S R}-T_{S N}}{T_{S R}-T_{0}}\right)
$$

where all temperatures are in Kelvin. From Eq. (7) the exergy loss due to entropy generation associated with heat transfer from $815^{\circ} \mathrm{C}$ to $200^{\circ} \mathrm{C}$ with ambient temperature of $25^{\circ} \mathrm{C}$ is 
calculated to be $49 \%$ of the original exergy, whereas if we meet the heat demand from low temperature heat source of $210^{\circ} \mathrm{C}$, the exergy loss due entropy generation associated with heat transfer becomes only 3\% of original exergy. This explains the improvement in efficiency by integrating a low-enthalpy heat source to meet the process heat demand.

Producing co-products or usable by-product can also change the efficiency of the system significantly. For instance, gypsum and ammonium acetate (4.8 MW, 16.8 MW equivalent of exergy, respectively) are produced in the detox process. If we can recover and utilize even $50 \%$ of these two wastes/by products, the overall efficiencies for case 1 , case 2 and case 3 increase to $35 \%, 37 \%$ and $42 \%$, respectively.

In summary, this analysis shows that, in essence, the lignin enriched residue is too valuable from a thermodynamic perspective to be combusted for process heat. This is therefore a thermodynamic justification for the biorefinery concept which proposes making the most out of the biomass by using the lignin-enriched residue as a feedstock for higher value products. For current technologies, to support this concept requires a source of low-temperature heat to meet process heat demands. Using a heat source with a temperature very close to that of process heat demand reduces the losses incurred by this approach. Potential sources of this heat are waste heat and geothermal. Overall, this process of integrating low-enthalpy heat and thus leaving the lignin enriched residue available for higher value uses can lead to significant improvements in overall efficiency of a biochemical biofuel process. This analysis also showed that if we can recover and utilize some of the key wastes and by-products, the overall efficiency increases due to the large exergy content in these chemicals.

\section{References}

[1] IEA, From 1st to 2nd Generation Generation Biofuel Technologies. 2008.

[2] Metzger, J.O. and A. Huttermann, Sustainable global energy supply based on lignocellulosic biomass from afforestation of degraded areas. Naturwissenschaften, 2008. 96: p. 279-288.

[3] Schmer, M.R., et al., Net energy of cellulosic ethanol from switchgrass. Proc. Natl. Acad. Sci. USA, 2008. 105: p. 464-469.

[4] Tilman, D., et al., Beneficial Biofuels-The Food, Energy, and Environment Trilemma. Science, 2009. 325: p. 270.

[5] Ragauskas, A.J., et al., The path forward for biofuels and biomaterials. Science, 2006. 311: p. 484-489.

[6] Demirbas, A., Biorefineries: Current activities and future developments. Energy Conversion and Management, 2009. 50(11): p. 2782-2801.

[7] Dodds, D.R. and R.A. Gross, Chemicals from Biomass. Science, 2007. 318: p. 12501251.

[8] Elnashaie, S.S.E.H., et al., Integrated system approach to sustainability bio-fuels and biorefineries. Bulletin of Science, Technology and Society, 2008. 28(6): p. 510-520.

[9] Zhang, Y.H.P., Reviving the carbohydrate economy via multi-product lignocellulose biorefinaries. J Ind Microbiol Biotechnol: BioEnergy- Special Issue, 2008. 35(5): p. 36775.

[10]Huber, G.W., S. Iborra, and A. Corma, Synthesis of Transportiation Fuels from Biomass: Chemistry, Catalysis, and Engineering. Chem. Rev., 2006. 106: p. 4044-4098. 
[11]Wooley, R., et al., Lignocellulosic Biomass toEthanol Process Design and Economics Utilizing Co-Current Dilute Acid Prehydrolysis and Enzymatic Hydrolysis Current and Futuristic Scenarios. 1999, National Reneable Energy Laboratory.

[12]Larsen, J., et al., The IBUS Process - Lignocellulosic Bioethanol Close to a Commercial Reality. Chem. Eng. Technol, 2008. 31(5): p. 765-772.

[13] Cardona Alzate, C.A. and O.J. Sánchez Toro, Energy consumption analysis of integrated flowsheets for production of fuel ethanol from lignocellulosic biomass. Energy, 2006. 31(13): p. 2447-2459.

[14]14. Piccolo, C. and F. Bezzo, A techno-economic comparison between two technologies for bioethanol production from lignocellulose. Biomass and Bioenergy, 2009. 33(3): p. 478-491.

[15] Szargut, J., D.R. Morris, and F.R. Steward, Exergy analysis of thermal, chemical, and metallurgical processes. 1988: Hemisphere publishing corporation.

[16]Dincer, I. and M.A. Rosen, Thermodynamic aspects of renewables and sustainable development. Renewable and Sustainable Energy Reviews, 2005. 9(2): p. 169-189.

[17]de Koeijer, G. and R. Rivero, Entropy production and exergy loss in experimental distillation columns. Chemical Engineering Science, 2003. 58(8): p. 1587-1597.

[18] Jarungthammachote, S. and A. Dutta, Thermodynamic equilibrium model and second law analysis of a downdraft waste gasifier. Energy, 2007. 32(9): p. 1660-1669.

[19]Lu, Y., et al., Thermodynamic modeling and analysis of biomass gasification for hydrogen production in supercritical water. Chemical Engineering Journal, 2007. 131(13): p. 233-244.

[20]Ojeda, K. and V. Kafarov, Exergy analysis of enzymatic hydrolysis reactors for transformation of lignocellulosic biomass to bioethanol. Chemical Engineering Journal, 2009. 154 (1-3), 390-395.

[21]Røsjorde, A. and S. Kjelstrup, The second law optimal state of a diabatic binary tray distillation column. Chemical Engineering Science, 2005. 60(5): p. 1199-1210.

[22]Prins, M.J., K.J. Ptasinski, and F.J.J.G. Janssen, Exergetic optimisation of a production process of Fischer-Tropsch fuels from biomass. Fuel Processing Technology, 2005. 86(4): p. 375-389.

[23]Talens, L., G. Villalba, and X. Gabarrell, Exergy analysis applied to biodiesel production. Resources, Conservation and Recycling, 2007. 51(2): p. 397-407.

[24]Tan, H.T., K.T. Lee, and A.R. Mohamed, Second-generation bio-ethanol (SGB) from Malaysian palm empty fruit bunch: Energy and exergy analyses. Bioresource Technology, 2010. 101 p. 5719-5727.

[25]Sohel, M.I. and M.W. Jack, Thermodynamic analysis of lignocellulosic biofuel production via a biochemical process: guiding technology selection and research focus. Bioresource Technology. DOI:10.1016/j.biortech.2010.10.032.

[26] Sohel, M.I. and M. Jack, Efficiency improvements by geothermal heat integration in a lignocellulosic biorefinery. Bioresource Technology 2010. 101 p. 9342-9347.

[27]Dincer, I. and M.A. Rosen, Exergy: energy, environment and sustainable development. 2007: Elsevier.

[28]DiPippo, R., Second Law assessment of binary plants generating power from lowtemperature geothermal fluids. Geothermics, 2004. 33(5): p. 565-586. 